\title{
O PROTAGONISMO INDÍGENA ENTRE CAMPOS MULTI E INTERDISCIPLINARES
}

LÍGIA DUQUE PLATERO ${ }^{1}$

UFRJ

\section{RESENHA}

LANGER, Protasio Paulo; CHAMORRO, Graciela (Org.). Missões, militância indigenista e protagonismo indígena: textos do XIII Jornadas Internacionais sobre as Missões Jesuíticas. São Bernardo do Campo:Nhanduti, 2012. 368p. v. 2.

Este livro é uma coletânea de artigos que abordam questões associadas às missões religiosas, à militância indigenista e ao protagonismo indígena. Os artigos reunidos orbitam ao redor das temáticas missões religiosas e conversão religiosa, educação, terras e reterritorialização, sempre associadas à questão do protagonismo indígena. Esse foi o eixo utilizado pelos autores para articular todos os artigos presentes nesta coletânea.

Os organizadores são a Dra. Graciela Chamorro e o Dr. Protasio Paulo Langer. Ela é doutora em Teologia e em Antropologia. Pesquisa nos povos Kaiowá e Guarani do Brasil desde 1983, com ampla experiência de pesquisa e uma destacada posição no campo acadêmico dos guaraniólogos. Chamorro atua nos campos da Linguística Histórica, das Religiões Indígenas e Missões Religiosas. Desde 2006, ela é

\footnotetext{
${ }^{1}$ Doutoranda em Antropologia pelo Programa de Pós-graduação em Sociologia e Antropologia (PPGSA) da Universidade Federal do Rio de Janeiro (UFRJ)e bolsista CAPES. Mestra em Estudos Latinoamericanos pela Universidade Nacional Autônoma do México (UNAM). Bacharel e licenciada em História pela Universidade de São Paulo (USP). E-mail: ligiaplatero@ gmail.com .
}

Espaço Ameríndio, Porto Alegre, v. 8, n. 2, p. 287-296, jul./dez. 2014. 
professora de História Indígena da Universidade Federal da Grande Dourados (UFGD), onde também é docente na Licenciatura Intercultural Indígena TekoArandu.

Já o Dr. Protasio Paulo Langer é graduado em filosofia, doutor em História pela Universidade Estadual Paulista (UNESP), em 2001, com pós-doutorado na Universidade Federal Fluminense (UFF). É professor da UFGD, onde ministra a disciplina História da América, no curso de História e Licenciatura Indígena Teko Arandu. Também atua na linha de História Indígena no Programa de Pós-graduação em História da UFGD. Entre suas produções, destaca-se o tema das missões religiosas e projetos civilizatórios entre os povos indígenas do período colonial.

A organização do livro reflete a formação disciplinar múltipla dos organizadores. Esta coletânea contém dezessete artigos e uma entrevista. Os artigos são provenientes de diversos campos e alguns deles são interdisciplinares. Do campo científico, há artigos da História, Etno-história, Etno-musicologia, Antropologia, Arqueologia, Geografia e Sociologia. Também há artigos da Teologia, o que para o leitor desavisado pode representar uma presença destoante e incômoda. Entretanto, a presença de artigos desta área se justifica devido à proposta da coletânea, que é a reunião de artigos que expressam as intrincadas relações interculturais e interpolíticas estabelecidas entre missionários, indigenistas e os povos indígenas na América do Sul.

Os artigos escolhidos para esta coletânea foram trabalhos apresentados nas XIII Jornadas Internacionais sobre as Missões Jesuíticas, realizada em Dourados, no Mato Grosso do Sul, de 30 de agosto a 03 de setembro de 2010². As Jornadas acontecem bianualmente desde 1996. Esse evento foi originado do Simpósio Nacional de Estudos Missioneiros de Santa Rosa, RS, evento bianual, que aconteceu entre 1975 a 1995.

Como afirmam os organizadores, esses eventos possuíam um teor teológico impulsionado pelo Concílio Vaticano II (1962 - 1965). A partir de então, setores eclesiásticos juntamente à Teologia da Libertação

\footnotetext{
${ }^{22} \mathrm{O}$ livro apresentado nesta resenha é a segunda coletânea de artigos apresentados nas XIII Jornadas. A primeira coletânea resultou no livro Fronteiras e Identidades - Encontros e Desencontros entre Povos Indígenas e Missões Religiosas, organizado por Graciela Chamorro, Thiago Leandro Vieira Cavalcante e Carlos Barros Gonçalves.
} 
elaboraram novas diretrizes para as missões católicas entre os povos indígenas.

Nesse contexto e sob a influência do Simpósio sobre friç̧ão interétnica na América do Sul, ocorrido em 1971, em Barbados, patrocinado pelo Programa Mundial de Combate ao Racismo do Conselho Mundial de Igrejas, houve uma influência mútua entre o campo religioso e o campo científico antropológico no Brasil. Pois antropólogos (como Darcy Ribeiro) e missionários passaram a criticar a política indigenista estatal e missionária de "integração" dos indígenas à sociedade nacional.

Devido ao diálogo entre missionários e antropólogos, foi estabelecido um novo discurso missiológico e acadêmico desde a década de 1970, estimulando a organização dos movimentos sociais indígenas e as suas lutas por protagonismo e autonomia.

Com a formação de órgãos eclesiásticos como o Conselho Indigenista Missionário (CIMI), vinculado à Conferência Nacional de Bispos do Brasil (CNBB), e o Conselho de Missão entre Povos Indígenas (Comin), essas organizações influenciaram também no campo dos movimentos sociais indígenas, visando à defesa dos direitos indígenas.

Sendo assim, as Jornadas são resultado dessa mudança de paradigma missiológico que propunha uma intensificação com o diálogo acadêmico e a adoção de uma postura política em apoio às causas indígenas. Daí vem a proposta do encontro, que leva à existência do presente livro. A proposta foi reunir artigos que tratam os indígenas como sujeitos de sua própria história, apesar da dominação colonial de agências missionárias ou estatais.

A ideia do protagonismo é o que une a grande diversidade de artigos presente neste livro. Este foi dividido em duas partes. $\mathrm{Na}$ primeira, os autores reuniram artigos sob o título Reflexões sobre Missões Religiosas e Protagonismo Indígena e, na segunda parte, foram reunidos artigos sob o título Protagonismo indígena: educação, terra e reterritorialização. Nesta resenha, preferi tratar dos artigos em blocos temáticos, que não correspondem à ordem exata elencada pelos autores.

Em um primeiro bloco, há dois artigos de caráter teológico. O primeiro, escrito pelo doutor em teologia Paulo Suess, aborda o 
histórico do CIMI, apresenta o seu projeto político-missionário e mostra como essa instituição influenciou na organização de movimentos indígenas. $\mathrm{O}$ artigo possui um tom propagandístico, institucional, mas apresenta muitas informações sobre a instituição. No artigo do teólogo Roberto E. Zwetsch, o autor se propõe a fazer um diálogo com o livro Deus na Aldeia de Paula Monteiro, afirmando que os missionários ganharam um status, na atualidade, de mediadores culturais. O autor chega à conclusão de que o protagonismo indígena poderia ser gerado por meio de teologias indígenas. Portanto, esses dois autores são claramente favoráveis à atuação do CIMI junto aos povos indígenas no Brasil.

Em um segundo bloco, há dois artigos de caráter histórico e etnohistórico. O primeiro, da antropóloga Dra. Isabelle Combès, trata das inter-relações de diversos povos indígenas na região do Chaco e suas conexões com as missões jesuíticas no período entre 1691 e 1767. A autora conclui que os Chiquitos tiveram relações com vários outros povos indígenas da região e também com as missões jesuíticas, mas a sua conversão religiosa não significava a adoção das crenças e da fé.

Já o artigo do doutorando em Antropologia Pablo Antunha Barbosa trata da formação de aldeamentos dos Guarani na fronteira entre São Paulo, Paraná e Mato Grosso, no século XIX. O autor conclui que, após a saída das missões dos aldeamentos da fronteira entre Paraná, São Paulo e Mato Grosso do Sul, houve uma "reguaranização" daquelas populações, que estavam "aculturadas". Nesse bloco, há a discussão do protagonismo desses povos indígenas na História. Os artigos se relacionam também à temática sobre território.

Em um terceiro bloco, há uma série de artigos que tratam da questão da conversão religiosa, de maneira histórica ou etnográfica. $\mathrm{O}$ artigo de Mauro Gomes da Costa aborda a atuação da Missão Salesiana em São Gabriel da Cachoeira (no Rio Negro, Amazonas), no primeiro quartel do século XX. O autor conclui que a população da região aceitou a presença da missão, pois as ações assistencialistas dos missionários supriam a ausência do Estado. Por outro lado, os indígenas perceberam as ações dos missionários como um amparo contra as explorações comerciais. 
No artigo da mestra em História Indígena Ana Maria Melo e Souza, a autora aborda a questão da influência do discurso pentecostal ao "modo de ser" kaiowá. A autora afirma que os Kaiowá contemporâneos passam por um processo de construção de si mesmos. No caso da Terra Indígena de Panambizinho, esse protagonismo se dá de duas maneiras. Por um lado, por meio da busca de retomada de rituais tradicionais por parte de uma parcela kaiowá da reserva. Por outro lado, a autora percebe a conversão religiosa ao pentecostalismo da igreja Deus é Amor como uma forma de ressignificação da sua religiosidade, que possibilita aos Kaiowá integrarem em seu modo de ser padrões e comportamentos da cultura não indígena, a fim de poderem transitar nesses dois universos.

No artigo de Carlos Barros Gonçalves, o autor apresenta uma pesquisa histórica e circunscreve a experiência protestante missionária da Associação Evangélica de Catequese dos Índios do Brasil, por meio das imagens dos Caiuá construídas pelo olhar dos agentes da missão nos jornais das Igrejas consorciadas, na ação evangelizadora/civilizatória. O autor faz uma exposição detalhada dos discursos que impulsionaram as ações de missionários protestantes comprometidos com o indigenismo de integração. O autor propõe a elaboração de uma nova utopia ecumênica por parte dos missionários protestantes.

O antropólogo Levi Pereira Marques já possui um lugar de destaque no campo dos guaraniólogos e publica pela segunda vez um artigo sobre o pentecostalismo kaiowá e guarani ${ }^{3}$. Este texto aborda a questão dos significados dos processos de conversão dos Kaiowá da reserva de Dourados a igrejas pentecostais. Para o autor, o processo de conversão dos Kaiowá às igrejas evangélicas se relaciona com a perda da eficácia "do modo antigo" de vida e dos rituais tradicionais dos xamãs. Segundo o autor, as conversões também são um aspecto do protagonismo indígena em relação à inovação cultural.

Ainda no grupo que aborda a questão da conversão religiosa, Gustavo Gomes dos Santos apresenta uma entrevista realizada com Édina Silva de Souza (Kunhá Apyká Rendy'í), da reserva indígena de Dourados, no Mato Grosso do Sul. O entrevistador aborda a questão da

${ }^{3}$ Ver Marques (2004).

Espaço Ameríndio, Porto Alegre, v. 8, n. 2, p. 287-296, jul./dez. 2014. 
presença das igrejas evangélicas naquela Terra Indígena e, de acordo com Édina, a maioria dos frequentadores de igrejas evangélicas da reserva continua possuindo crenças associadas ao sistema tradicional e faz um equilíbrio entre esses dois sistemas de crenças. Para ela, o principal impeditivo para a continuação do sistema de crenças tradicionais na reserva foi a destruição da floresta e a consequente ruptura da conexão dos Kaiowá e dos Guarani com a natureza.

Em outro grupo de artigos, há a discussão sobre as lutas pelo reconhecimento do Estado brasileiro do patrimônio cultural dos Guarani-Mbya. O artigo de José Otávio Catafesto de Souza (et al.) trata dos significados atribuídos pelos Guarani-Mbya às ruínas de Tava Miri São Miguel Arcanjo, no município São Miguel das Missões, no Rio Grande do Sul, que foi um local de missão jesuítica. Os autores enfatizam sua imagem como manifestação degradada da antiga morada das divindades. De acordo com os autores, os mitos e os significados atribuídos às ruínas se relacionam com a ordem política e ideológica, pois o protagonismo indígena é explicitado nas lutas e reivindicações dos Guarani-Mbya pelo reconhecimento formal do Estado brasileiro desse sítio enquanto lugar de referência cultural mbyá-guarani.

$\mathrm{O}$ artigo citado possui muitas relações e semelhanças com o texto de José Otavio Catafesto e José Cirilo Pires, que também aborda a questão dos significados míticos, cosmológicos e históricos atribuídos pelos Mbya-Guarani à Missão de São Miguel (ou Ta'angá Tava Miri), no Rio Grande do Sul. Para estes dois autores, São Miguel é um importante lugar de referência cultural para os Mbyá-Guarani, pois, para eles, as ruínas são ta angá da morada dos deuses, como os insetos, aves e animais são imagens decaídas dos antigos Guarani que ficaram enredados nas paixões terrenas e perderam sua condição de imortalidade. Os dois artigos possuem muita similaridade em suas problemáticas e conclusões, mas o segundo enfatiza mais a descrição da cosmologia dos Guarani-Mbya e o primeiro assume uma discussão mais política.

$\mathrm{Na}$ segunda parte do livro, os organizadores apresentaram artigos relacionados à questão da educação indígena, das terras e territorialização. Entre os artigos que abordam a questão educativa, o trabalho do historiador Cássio Knappdiscorre sobre a experiência da 
missão evangélica Summer Institute of Linguistcs (SIL) na formação de monitores bilíngues kaingang por meio do curso normal bilíngue, realizado no Centro de Treinamento Profissional Clara Camarão (CTPCC), no Município de Tenente Portela, em 1970. O autor conclui que esse primeiro curso de formação bilíngue não foi satisfatório do ponto de vista da comunidade kaingang, pois serviu mais aos interesses de evangelização do SIL do que aos da comunidade.

O artigo do teólogo e indigenista Sandro Luckmann trata da atuação missionária e indigenista no âmbito da educação escolar da Igreja Evangélica de Confissão Luterana no Brasil (IECLB) e do Comin. O autor defende o projeto do Comin, adotando um discurso político institucional da própria missão.

O artigo do doutorando em História Cultural Clovis Antonio Brighenti e da Dra. Graciela Chamorro problematiza as propostas apresentadas pelos Guarani, Mbya e Ñandeva, em um documento no Seminário sobre a educação escolar guarani no sul e sudeste brasileiro, realizado em Florianópolis, Santa Catarina, em 2001. Os autores problematizam também a relação entre escolas e terras indígenas. $\mathrm{Na}$ avaliação dos autores, "somente com a demarcação das TI a escola poderá se tornar um lugar bom para se pensar e desenvolver a educação escolar indígena, sem rivalizar com as outras instituições que lideram o processo de educação indígena" (BRIGHENTI e CHAMORRO, 2012, p.258).

Em outro agrupamento de artigos que abordam diretamente a questão dos territórios, a socióloga Célia Maria Foster Silvestre e a antropóloga Lauriene Seraguza Olegário Souza abordam a questão dos conflitos fundiários no Mato Grosso do Sul, em 2009, associados às lutas pela demarcação de Terras Indígenas dos Kaiowá e Guarani. As autoras narram histórias de violência contra essas famílias participantes das lutas pela retomada das terras. De acordo com as autoras, as experiências de conflito e violência dos Kaiowá e Guarani citados no artigo são o resultado de um processo de territorialização, empreendido pelo Estado, que desconsiderou a dinâmica de territorialidade dos Guarani e Kaiowá.

Ainda no grupo sobre territórios, a geógrafa Juliana Grasiéli Bueno Mora fez uma discussão sobre o sistema-mundo moderno a partir das 
construções teóricas de Carlos Walter Porto-Gonçalves, para tratar dos discursos contrários à demarcação das terras e territórios dos Guarani e Kaiowá. A autora conclui que as lutas dos Kaiowá e Guarani pelo retorno aos tekohá são lutas que buscam resistir ao desenvolvimento do capitalismo no campo, tornando-se lutas que se colocam em oposição e enfrentamento à colonialidade.

O artigo do antropólogo Aloir Pacini apresenta uma análise de mapas associados ao território e a identidade étnica chiquitana na fronteira Brasil-Bolívia. De acordo com o autor, esses mapas são instrumentos fundamentais para a análise da formação dos Estados nacionais e da identidade étnica desse povo indígena. $\mathrm{O}$ autor conclui que os mapas são marcos concretos do contato, mistura e diferenciação entre comunidades chiquitanas e o Estado nacional, sendo que algumas comunidades se identificam como indígenas e outras rechaçam esta possibilidade.

O artigo do Dr. Protasio Paulo Langer é o único que faz uma interlocução entre a Etno-musicologia e a História. O autor mostra dados históricos e etnográficos que indicam que, além dos Mbya, os guarani-falantes do sul do Mato Grosso do Sul conhecem, praticaram ou ainda praticam instrumentos musicais de corda com arco como o rave (rabeca ou violino) e o mbaraka (neste caso, um violão de cinco cordas). Os dados etnográficos e históricos foram um primeiro passo para um estudo mais sistemático das possíveis aproximações entre o legado jesuítico missioneiro e a música das comunidades guarani-falantes contemporâneas.

O protagonismo indígena é uma questão que aparece em todos os artigos, de maneira explícita ou implícita. Entretanto, o livro adota em seu conjunto uma perspectiva muito próxima da proposta política e teológica do CIMI.Teria sido interessante se estivesse incluído no livro algum artigo que analisasse com uma perspectiva crítica o trabalho dessa instituição desde as Ciências Sociais, e não apenas com um olhar teológico "nativo". Teria sido enriquecedora também a inclusão de uma entrevista com algum indígena ligado diretamente aos movimentos indígenas que pudesse dar seu depoimento sobre a participação do CIMI junto a esses movimentos sociais. 
Sendo assim, no lugar de protagonismo, prefiro a utilização do conceito autonomia, proveniente da interlocução entre antropólogos e o campo político dos movimentos sociais indígenas na América Latina.

A maioria dos artigos está bem escrita, embora alguns não tenham definido claramente a sua problemática na introdução. O livro possui uma grande variedade temática e disciplinar em seus artigos, o que certamente representou um desafio para a organização. Alguns artigos ficaram isolados devido à temática muito diversificada.

Apesar dos pequenos problemas apontados, este livro traz uma contribuição importante por trazer uma grande diversidade de trabalhos que tratam de temas interligados. Essa diversidade temática abre espaço para novas e amplas discussões nos campos multi e interdisciplinares. $O$ livro é importante principalmente para as áreas da Etnologia, Antropologia Política e Antropologia da Religião, História indígena, História das missões religiosas, Movimentos Sociais Indígenas e Teologia.

A maioria dos artigos abordam questões vinculadas aos povos Guarani, apesar de haver artigos que apresentem pesquisas em outros povos indígenas sul-americanos. Sendo assim, o livro se torna uma referência para os guaraniólogos.

Outro aspecto valioso do livro é que os artigos foram escritos por pesquisadores de vários níveis: desde jovens pesquisadores com titulação de mestre, com pesquisas de excelente nível acadêmico, até doutores ou doutoras consagrados. Essa abertura para jovens pesquisadores fortalece o debate, que perpassa os campos científicos, o campo político e o campo religioso.

Por último, após a leitura deste livro e de outras pesquisas sobre a temática, considero que uma efetiva laicidade do Estado promoveria mais justiça social e autonomia do que uma ajuda "desinteressada" de missões militantes que, na realidade, buscam a promoção de cristianismos e teologias indígenas.

\section{Referências bibliográficas}

Espaço Ameríndio, Porto Alegre, v. 8, n. 2, p. 287-296, jul./dez. 2014. 
LÍGIA DUQUE PLATERO - O protagonismo indígena entre campos multi e interdisciplinares

BRIGHENTI, Clovis Antonio; CHAMORRO, Graciela. Territorialidade e educação escolar indígena: desafios da experiência Guarani em Santa Catarina. In: LANGER, Protasio Paulo; CHAMORRO, Graciela (Org.). Missões, militância indigenista e protagonismo indígena: textos do XIII Jornadas Internacionais sobre as Missões Jesuíticas. São Bernardo do Campo: Nhanduti, 2012. v. 2. p. 243-260.

LANGER, Protasio Paulo; CHAMORRO, Graciela (Org.). Missões, militância indigenista e protagonismo indígena: textos do XIII Jornadas Internacionais sobre as Missões Jesuíticas. São Bernardo do Campo:Nhanduti, 2012. v. 2.

MARQUES, Levi Pereira. O pentecostalismo Kaiowá: uma aproximação dos aspectos Sociocosmológicos e Históricos. In: WRIGHT, Robin M. (Org). Transformando os deuses: igrejas evangélicas, pentecostais e neopentecostais entre os povos indígenas no Brasil. Campinas: Unicamp, 2004. v. 2. p. 267-302.

CHAMORRO, Graciela; CAVALCANTE, Thiago Leandro Vieira; GONÇALVES, Carlos Barros (Org.). Fronteiras e identidades. Encontros e Desencontros entre Povos Indígenas e Missões Religiosas: XIII Jornadas Internacionais sobre as Missões Jesuíticas. São Bernardo do Campo: Nhanduti, 2011.

Espaço Ameríndio, Porto Alegre, v. 8, n. 2, p. 287-296, jul./dez. 2014. 